\title{
Thermodynamic properties of uranium in Ga-In based alloys
}

\author{
V.A. Volkovich a,*, D.S. Maltsev ${ }^{\text {a }}$, L.F. Yamshchikov ${ }^{a}$, S.Yu Melchakov ${ }^{a}$, A.V. Shchetinskiy ${ }^{a}$, \\ A.G. Osipenko ${ }^{\text {b }}$, M.V. Kormilitsyn ${ }^{\mathrm{b}}$ \\ a Department of Rare Metals and Nanomaterials, Institute of Physics and Technology, Ural Federal University, Ekaterinburg 620002, Russia \\ ${ }^{b}$ JSC “State Scientific Centre - Research Institute of Atomic Reactors", Dimitrovgrad 433510, Russia
}

\section{A R T I C L E I N F O}

\section{Article history:}

Received 30 October 2012

Accepted 8 March 2013

Available online 20 March 2013

\begin{abstract}
A B S T R A C T
Activity of uranium was determined in gallium, indium and gallium-indium eutectic ( $21.8 \mathrm{wt} . \%$ In) based alloys between 573 and $1073 \mathrm{~K}$ employing the electromotive force method. In two-phase U-Ga-In alloys, uranium forms the intermetallic compound $\mathrm{UGa}_{3}$. Activity coefficients and solubility of uranium in Ga-In eutectic were also determined in the same temperature range. Partial thermodynamic functions of $\gamma-\mathrm{U}$ in saturated alloys with gallium, indium and Ga-In eutectic were calculated.
\end{abstract}

(c) 2013 Elsevier B.V. All rights reserved.

\section{Introduction}

Pyrochemical reprocessing of spent nuclear fuels (SNFs) employing fused salts and liquid metals as working media is considered as a possible alternative to the existent solvent extraction (PUREX) process. Molten salts and metals exhibit very high radiation and thermal stability and therefore can be used for reprocessing irradiated fuels from thermal and fast neutron reactors with a high burn-up after a relatively short cooling time. Inorganic melts are generally not efficient in moderating neutrons thus allowing working with more concentrated (as to fissile material) systems. One of the ways for separating elements present in SNF involves dissolution of the fuel in a salt melt and selective extraction of desired elements by liquid metals. The liquid state of salts and metals simplifies phase separation. Liquid gallium is efficient in separating uranium from lanthanides with the separation coefficients of several orders of magnitude higher than for any other low-melting metals ( $\mathrm{Zn}, \mathrm{Sn}, \mathrm{Pb}, \mathrm{Bi}, \mathrm{In}, \mathrm{Cd}, \mathrm{Tl}$ ). Available thermodynamic data [1] show that, for example, separation coefficient for uranium (fissile material) and lanthanum (fission product) in $3 \mathrm{LiCl}-2 \mathrm{KCl}$ melt - liquid gallium system at $800-1000 \mathrm{~K}$ is around $10^{4}$.

One of the disadvantages of pyrochemical reprocessing is relatively high working temperatures. Lowering them is desirable from the technological point of view since it reduces energy consumption and simplifies finding suitable construction materials. Binary or ternary alloys of eutectic compositions can be employed to lower the melting point of the metal phase. However, up to date only binary systems of actinides and some low-melting metals were studied and the information on the ternary and more complicated systems is essentially non-existent.

\footnotetext{
* Corresponding author.

E-mail address: volkovich@dpt.ustu.ru (V.A. Volkovich).
}

Gallium-indium eutectic with the melting point around $289 \mathrm{~K}$ is one of the lowest melting gallium containing binary alloys. The behavior of metallic eutectic mixtures is close to the ideal and therefore their vapor pressure, for example, can be estimated employing the additivity rule. Calculations performed using the available data on gallium and indium vapor pressures [2] show that at even at $1100 \mathrm{~K}$ the equilibrium vapor pressure above the $\mathrm{Ga}$-In eutectic will be only $1.5 \times 10^{-4} \mathrm{~mm} \mathrm{Hg}$. Wide temperature range of the liquid state and low vapor pressure make the Ga-In alloy quite attractive for employing in pyrochemical partitioning technologies. The efficiency of the separation process taking place on the "molten saltliquid metal" interface depends on the properties of the elements of interest in both salt and metallic phases. Before evaluating the feasibility of separating the SNF components, the thermodynamic properties of uranium and fission product elements must be studied in the salt as well as in the liquid metal phase.

The phase diagram of the ternary Ga-In-U system has not been studied so far. There is a sufficient body of data concerning the binary Ga-U system, however the diagram of In-U system is still nonexistent. The Ga-U system contains three intermetallic compounds, $\mathrm{UGa}_{3}, \mathrm{U}_{3} \mathrm{Ga}_{5}$ and $\mathrm{UGa}_{2}[3,4]$. Previously reported $\mathrm{U}_{2} \mathrm{Ga}_{3}$ phase has, in fact, the composition of $\mathrm{U}_{3} \mathrm{Ga}_{5}[5,6]$. Thermodynamic properties of U-Ga alloys were determined from the results of electrochemical, gallium vapor pressure and calorimetry measurements, as well as thermodynamic calculations, and these include $\Delta G, \Delta H$ and $\Delta S$ of formation of $\mathrm{UGa}_{3}$ compound [7-12]. Electronic structure of $\mathrm{UGa}_{3}$ was determined employing various spectroscopy techniques [13]. Solubility of uranium in liquid gallium was determined between 643 and $1013 \mathrm{~K}[7,14]$. Only one compound, $\mathrm{UIn}_{3}$, was so far identified in the In-U system and thermodynamic properties of this phase were determined employing the electromotive force and indium vapor pressure measurements [7-9]. Uranium solubility in liquid indium was measured above $612 \mathrm{~K}$ using various techniques $[7,14,15]$. 
Metallic uranium has three modifications $(\alpha, \beta$ and $\gamma)$ in the solid state and in various works the authors took different states for the standard. To enable the comparison of available information the reported data must be brought to the same standard state. In the present study $\gamma$-uranium and super cooled liquid uranium were chosen as the standard states. The aim of the present work was studying the behavior of uranium in the Ga-In eutectic alloy and determining thermodynamic characteristics, activity, activity coefficients, and solubility of uranium in the said alloy.

\section{Experimental}

The electromotive force (EMF) method was chosen in the present work for studying uranium behavior in liquid alloys. The measurements were performed between 573 and $1073 \mathrm{~K}$. To determine uranium activity and activity coefficients, the EMF of the following galvanic cell was measured:

$(-) \mathrm{U}\left|\mathrm{LiCl}-\mathrm{KCl}-\mathrm{CsCl}-\mathrm{UCl}_{3}\right| \mathrm{U}+\mathrm{Me}(+)$,

where Me is the low melting metal (Ga, In or Ga-In eutectic). Uranium metal does not noticeably react with alkali chloride based melts containing dissolved uranium(III) chloride [16-19] and therefore can be safely employed as the reference electrode. Low melting ternary $\mathrm{LiCl}-\mathrm{KCl}-\mathrm{CsCl}$ eutectic $(57.5 \mathrm{~mol} . \% \mathrm{LiCl}$ and $16.5 \mathrm{~mol} \% \mathrm{KCl}$, m.p. $536 \mathrm{~K}$ ) was used as the solvent salt. Individual alkali metal chlorides (purity of $99.5 \%$ and above) were dried under vacuum at 773-873 K for several hours, then melted and dry hydrogen chloride was bubbled through the melt for about three hours to remove trace water and convert oxide impurities to the corresponding chlorides. The salt mixtures containing $\mathrm{U}(\mathrm{III})$ chloride (around 3-5 wt.\% uranium), were prepared by anodic dissolution of uranium metal in the chloride eutectic. Gallium-indium alloys of the eutectic composition (21.8 wt.\% In [20]) were prepared by fusing individual metals (Ga of 99.9999\% purity and In of 99.9995\%) in an argon filled dry box MBraun Unilab 1200/780. Ternary U-Ga-In alloys were obtained by adding metallic uranium or uranium-gallium alloy (containing ca. $5 \mathrm{wt}$.\% U) to the gallium-indium eutectic, or by cathodic deposition of uranium on the liquid Ga-In alloy directly in the experimental cell.

The electrochemical measurements were performed under argon in the experimental cell schematically shown in Fig. 1. Commercial purity argon was passed through zirconium turnings heated to $973 \mathrm{~K}$ to remove any trace oxygen impurity. All the ceramic parts (crucibles, thermocouple sheath, etc.) contacting with uranium containing melts or alloys were made of beryllium oxide to minimize possible interaction of uranium and $\mathrm{U}(\mathrm{III})$ chlorospecies, having high affinity for oxygen, with the ceramics. The cell was assembled and closed in the argon dry box, then taken out and positioned in a vertical tube furnace. The cell was then evacuated and filled with argon. After the atmosphere in the cell was changed three times the cell was heated to the required temperature and the electrochemical measurements started. Additional purification of the atmosphere in the cell from residual oxygen and moisture was achieved by placing zirconium turnings (acting as a getter) in the bottom part of the cell, Fig. 1. At highest working temperatures (973-1073 K) Zr getter inside the cell ensured that concentrations of oxygen and water were negligibly low. Metallic uranium bar attached to a molybdenum rod acted as the reference electrode and the electrode potentials of the liquid alloys were measured at zero current employing the Autolab PGStat $302 \mathrm{~N}$ potentiostat. At a fixed temperature the potentials were considered as stationary if they did not exhibit a tendency to monotonous change and did not change more than by $0.1-0.5 \mathrm{mV}$ over an hour. At such conditions the potentials of the alloys of the same phase composition were reproducible within $\pm 0.1-0.2 \mathrm{mV}$. Time required

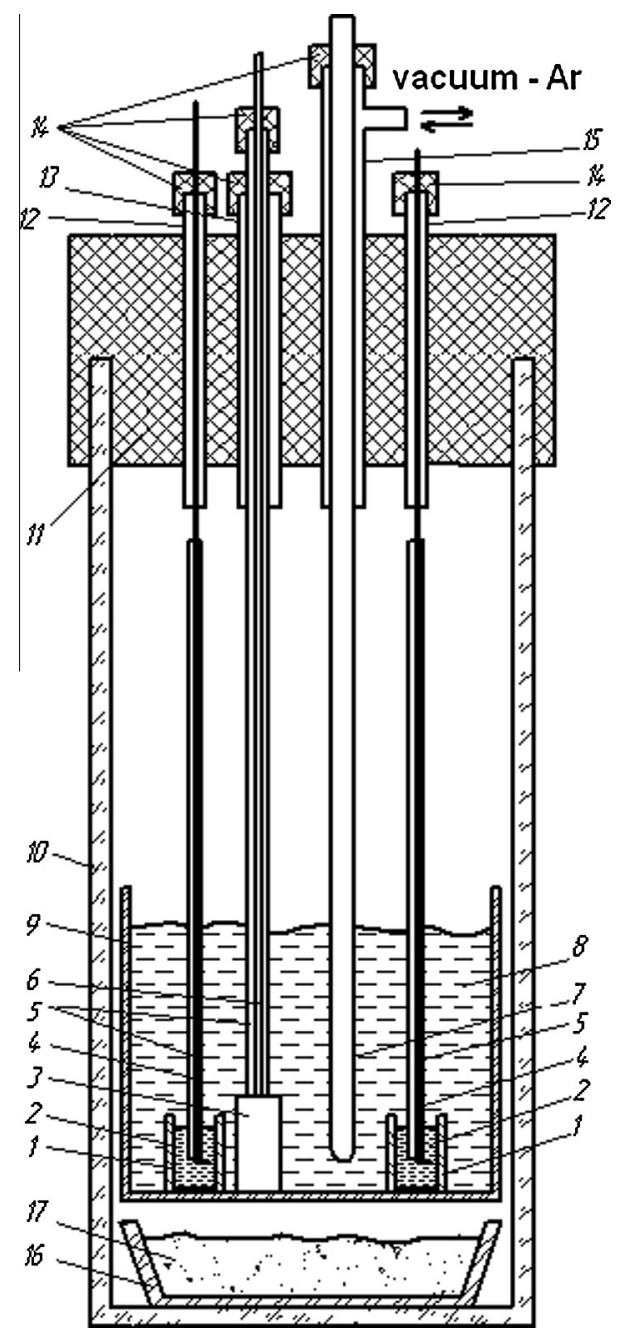

Fig. 1. Experimental cell for measuring e.m.f. of $\mathrm{U}\left|\mathrm{MCl}-\mathrm{UCl}_{3}\right| \mathrm{U}+\mathrm{Ga}-\mathrm{In}$ galvanic cell.1 - small beryllium oxide crucible; 2 - liquid alloy; 3 - metallic uranium (reference electrode); 4, 6 - current conductors; 5 - ceramic tube; 7 - beryllium oxide thermocouple sheath; 8 - molten salt electrolyte; 9 - large beryllium oxide crucible; 10 - silica cell; 11 - rubber stopper; $12,13,15$ - silica positioning tubes; 14 - rubber stoppers; 16 - alumina crucible; 17 - zirconium turnings.

for reaching first stable potential readings was 5-6 h. The following stationary values of the EMF (upon changing temperature) were reached after $1-3 \mathrm{~h}$. In a single experiment the potentials were normally measured starting from the highest temperature. The cell then was cooled in steps of $\mathrm{ca} .50^{\circ}$ and the potentials measured over selected temperature interval. After taking the readings at all required temperatures the cell could be heated again and the cycle repeated if desired. To check the reproducibility of data in a special series of experiments the EMF measurements were performed by varying the temperature from high temperature down and then back in steps of ca. $50 \mathrm{~K}$. The melt temperature was measured by a $K$-type thermocouple (Omega Engineering, Inc.) dipped into the salt melt and protected by a beryllium oxide sheath.

Current conductors to the liquid alloys were made of tungsten wire to minimize possible interaction with the liquid metals. Since the current conductor to uranium reference was made of molybdenum a correction for the thermal EMF between molybdenum and tungsten has to be made to the results of the electrochemical measurements. At the working temperatures Mo-W thermal EMF is small and between 280 and $1500 \mathrm{~K}$ it can be calculated from the following equation derived from the available literature data [21]: 
$\Delta E_{(\mathrm{Mo}-\mathrm{W})}=4.27 \times 10^{-6} \cdot T^{2}-7.88 \times 10^{-3} \cdot T+1.84, \mathrm{~V}$.

After completing the measurements the cell was allowed to cool and the quenched salt was dissolved in cold distilled water. The liquid alloys were washed with water and ethanol and dried at room temperature. The alloys were then dissolved in a mixture of nitric and hydrochloric acids and the solutions were analyzed by ICP-MS spectrometry. Analysis showed that there was no appreciable changes in uranium concentration in the metallic alloys in comparison with the starting values.

Gamma-uranium and super cooled liquid uranium were taken as the reference states when determining uranium activity and activity coefficients. To account for uranium phase transformations the following correction was added to the experimentally measured electrode potentials:

$\Delta E=-\left(\frac{R \cdot T}{n \cdot F}\right) \cdot \ln a_{0}$,

where $a_{0}$ is uranium activity at working temperature relative to $\gamma$ uranium or liquid uranium. The value of $\ln a_{0}$ was calculated from the known thermodynamic parameters of uranium phase transitions $[22,23]$. For example, activity of $\alpha$-U relative to $\gamma$-U can be calculated from the following expression:

$R \cdot \ln a_{0}=\frac{\Delta H_{\alpha}}{T_{\alpha} \cdot T} \cdot\left(T_{\alpha}-T\right)+\frac{\Delta H_{\beta}}{T_{\beta} \cdot T} \cdot\left(T_{\beta}-T\right)$,

where $\Delta H_{\alpha}$ and $T_{\alpha}$ are the enthalpy change and temperature of the $\alpha \rightarrow \beta$ transition, $\Delta H_{\beta}$ and $T_{\beta}$ are the same parameters of the $\beta \rightarrow \gamma$ transition.

\section{Results and discussion}

Uranium activity in the liquid metal phases was determined from the results of measuring EMF of heterogeneous (two-phase) alloys saturated with uranium. Activity coefficients were calculated from the results of EMF measurements of dilute (homogeneous) alloys with known uranium concentration. Uranium solubility in the liquid $\mathrm{Ga}$-In eutectic based alloys was estimated from the difference of obtained temperature dependencies of activity and activity coefficients.

\subsection{Activity of uranium in alloys with Ga-In, Ga, In}

The experimental temperature dependence of EMF of cell (1) containing two-phase $\mathrm{U}-\mathrm{Ga}-\mathrm{In}$ alloys is presented in Fig. 2. Twelve

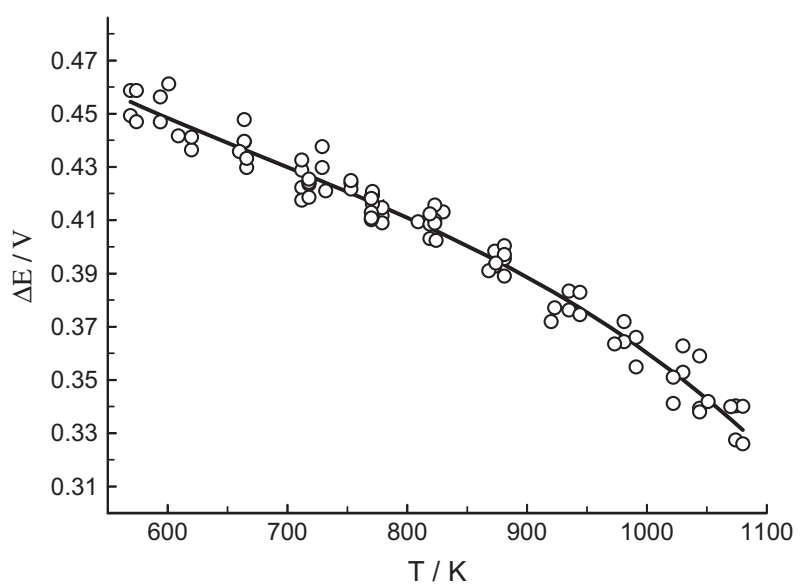

Fig. 2. The effect of temperature on e.m.f. of U-Ga-In alloys saturated with uranium. Reference electrode - uranium metal. Uranium concentration in the metallic phase in various samples was $0.1-10$ mol.\% (depending on temperature). separate alloy samples with various uranium concentrations were measured and showed good agreement of EMF values. In the studied temperature range the $E=f(T)$ dependence is non-linear. Non-linearity of the temperature dependence of EMF of two-phase U-Ga alloys was previously noted by Johnson and Feder [7] and subsequently by Lebedev et al. [8]. The latter associated the change in slope of this temperature dependence with the polymorphic transition in $\mathrm{UGa}_{3}$, by analogy with $\mathrm{PuGa}_{3}$ compound [24]. Subsequent investigations of U-Ga system, however, did not confirm the existence of two crystal modifications of $\mathrm{UGa}_{3}$. Chiotti et al. [25] discussed a number of possible reasons that might cause the change in slope of EMF dependence and concluded that a number of factors contribute to the observed behavior. The results obtained in the present study between 569 and $1080 \mathrm{~K}$ for U-Ga-In alloys saturated with uranium are satisfactorily described by the following equations (with $\gamma$-uranium and liquid uranium taken as the standard states):

$E_{\gamma-\mathrm{U}(\mathrm{Ga}-\mathrm{In})}=-2.107 \times 10^{-4} \cdot \mathrm{T}+0.584( \pm 0.010 \mathrm{~V}), 569-830 \mathrm{~K}$

$E_{\gamma-\mathrm{U}(\mathrm{Ga}-\mathrm{In})}=-3.106 \times 10^{-4} \cdot T+0.668( \pm 0.012 \mathrm{~V}), 830-1080 \mathrm{~K}$

$E_{1-\mathrm{U}(\mathrm{Ga}-\mathrm{In})}=-2.319 \times 10^{-4} \cdot T+0.614( \pm 0.010 \mathrm{~V}), 569-830 \mathrm{~K}$

$E_{1-\mathrm{U}(\mathrm{Ga}-\mathrm{In})}=-3.324 \times 10^{-4} \cdot T+0.699( \pm 0.012 \mathrm{~V}), 830-1080 \mathrm{~K}$

Statistical analysis of the experimental data was performed employing $t$-distribution with $95 \%$ confidence interval throughout the present work.

Cooled samples of two-phase U-Ga-In alloys contained crystals of 15-30 $\mu \mathrm{m}$ in size, Fig. 3. X-ray powder diffraction analysis, Fig. 3, showed that these crystals were $\mathrm{UGa}_{3}$ intermetallic compound. Since the peak positions in the diffraction pattern corresponded
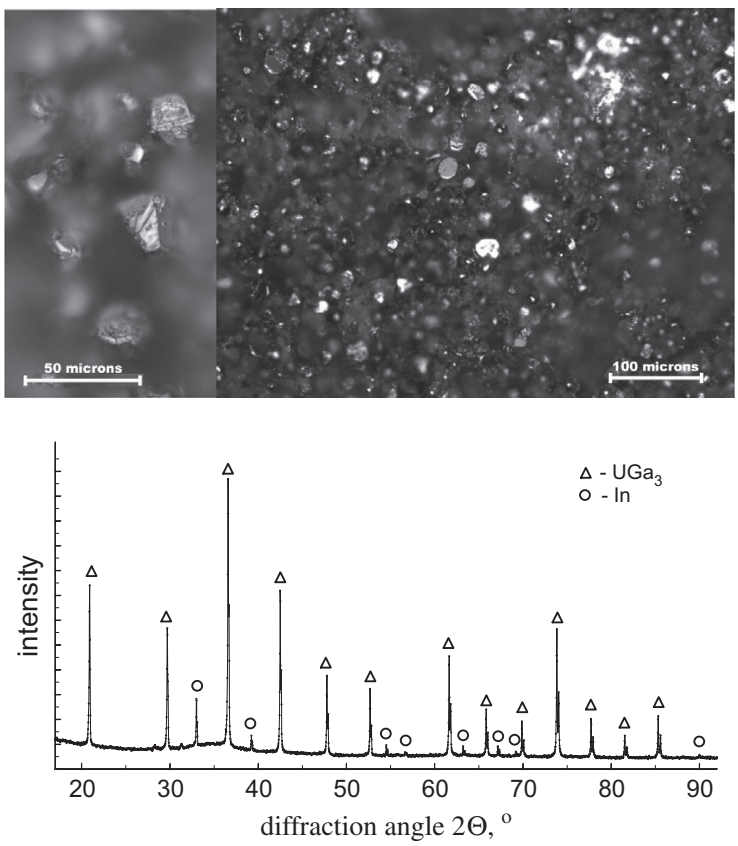

Fig. 3. Crystals formed in two-phase U-Ga-In alloys (above) and X-ray diffraction pattern of the alloy (below). 
exactly to those for $\mathrm{UGa}_{3}$ it can be concluded that no indium was entering the crystal lattice and $\mathrm{UGa}_{3}$ is the sole phase present in equilibrium with saturated U-Ga-In alloys. No peaks that could be attributed to uranium or gallium were observed. Gouder et al. [13] studied deposition of $\mathrm{UGa}_{3}$ thin films and reported that increasing temperature results in enrichment of the surface layer of this intermetallic compound by gallium. In the present study we have not observed excessive gallium in the crystals formed in U-Ga-In alloys.

Activity of $\gamma-U$ and super cooled liquid uranium in the Ga-In eutectic based alloys were calculated from the measured EMF values and at $569-1080 \mathrm{~K}$ they are described by the following equations:

$$
\begin{aligned}
& \operatorname{1ga}_{\gamma-\mathrm{U}(\mathrm{Ga}-\mathrm{In})}=3.76-9.23 \times 10^{3} \cdot T^{-1}( \pm 0.26) \\
& \operatorname{1ga}_{1-\mathrm{U}(\mathrm{Ga}-\mathrm{In})}=4.09-9.69 \times 10^{3} \cdot T^{-1}( \pm 0.26)
\end{aligned}
$$

Activity of uranium in binary U-Ga and U-In alloys was so far determined only at relatively high temperatures, the lowest being $696-1084 \mathrm{~K}$ for U-Ga and $626-1130 \mathrm{~K}$ for U-In systems $[7,14,15]$. It was therefore of interest to determine uranium activity in alloys with Ga and In at lower temperatures employed in the present work. The results obtained for $\gamma$-uranium in U-Ga and U-In alloys at $573-1073 \mathrm{~K}$ are described by the following equations:

$$
\begin{aligned}
& \lg \mathrm{a}_{\gamma-\mathrm{U}(\mathrm{Ga}-\mathrm{In})}=3.15-8.83 \times 10^{3} \cdot T^{-1}( \pm 0.08) \\
& \lg \mathrm{a}_{\gamma-\mathrm{U}(\mathrm{Ga}-\mathrm{In})}=4.01-6.89 \times 10^{3} \cdot T^{-1}( \pm 0.23)
\end{aligned}
$$

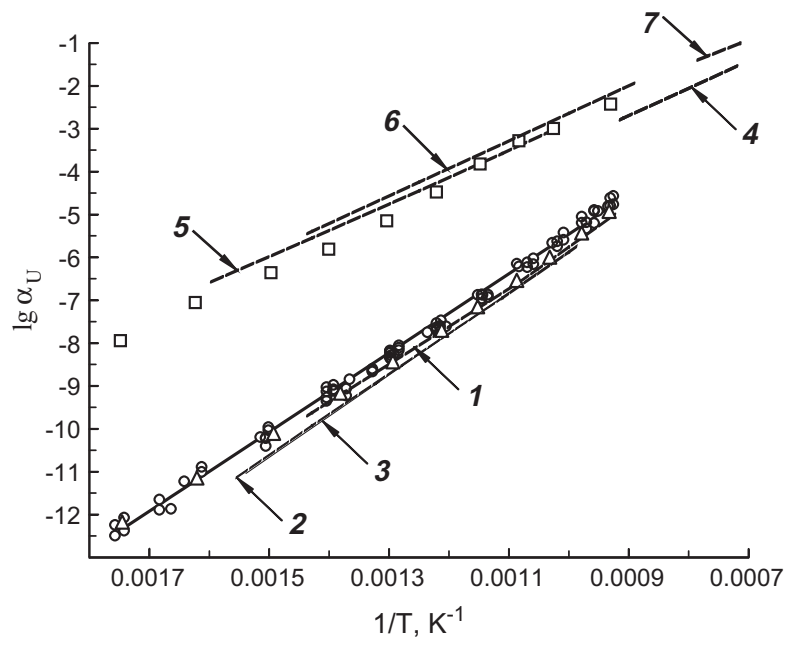

Fig. 4. Activity of $\gamma-U$ in $U-I n, U-G a$ and $U-G a-I n$ alloys. Symbols show the results obtained in the present work for the alloys based on Ga-In $(\bigcirc)$, Ga $(\Delta)$, In $(\square)$. Dashed lines show the literature data: 1-4 - U-Ga [7-10], 5-7 - U-In [7,9,15]. and agree very well with the existing literature data.

Comparison of $\gamma$-uranium activity in U-Ga-In, U-Ga and U-In alloys, Fig. 4, shows that uranium activity in the alloys based on the Ga-In eutectic is sufficiently lower than in the In-based alloys and very close to the activity of uranium in the alloys with gallium. Our measurements showed that the activity of uranium in Ga-In eutectic and gallium based alloys is essentially identical below $660 \mathrm{~K}$. This again indicates that the same intermetallic phase, i.e., $\mathrm{UGa}_{3}$, is present in the equilibrium with the liquid phase in alloys with Ga-In and Ga. Partial thermodynamic functions of $\gamma-\mathrm{U}$ in Ga, In and Ga-In eutectic based alloys were calculated and presented in Table 1.

\subsection{Activity coefficients of uranium in U-Ga-In alloys}

Activity coefficients of uranium in Ga-In eutectic based alloys were determined from the EMF measurements of dilute (homogeneous) U-Ga-In alloys and at 574-1076 K they are approximated by the following expressions:

$1 \mathrm{~g} \gamma_{\gamma-\mathrm{U}(\mathrm{Ga}-\mathrm{In})}=4.11-6.79 \times 10^{3} \cdot T^{-1}( \pm 0.71)$

$1 \mathrm{~g} \gamma_{1-\mathrm{U}(\mathrm{Ga}-\mathrm{In})}=4.83-7.55 \times 10^{3} \cdot T^{-1}( \pm 0.70)$

Uranium activity coefficients in Ga-In based alloys determined in the present work are very close to those in U-Ga alloys and substantially lower than in U-In system, Fig. 5.

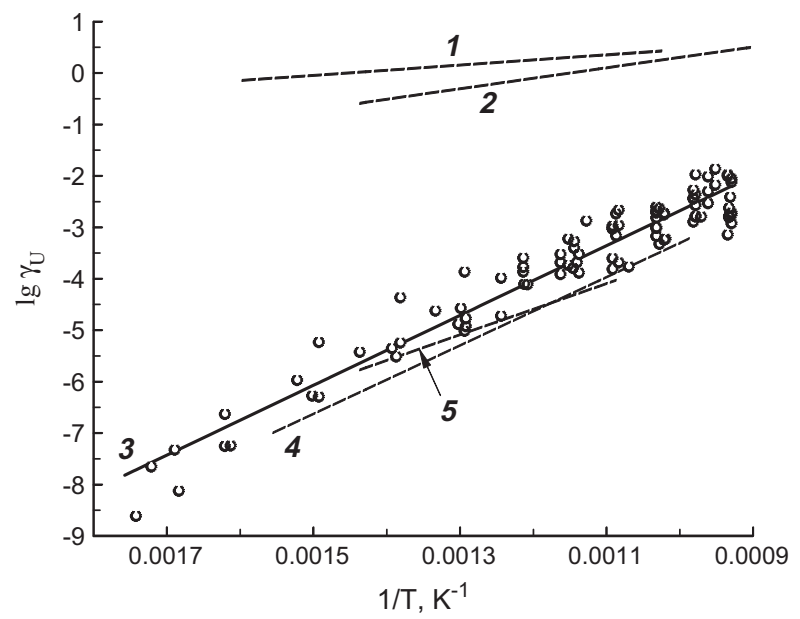

Fig. 5. Activity coefficients of $\gamma-U$ in liquid alloys with indium (1 and 2) [7,15],

\begin{tabular}{|c|c|c|c|c|c|}
\hline System & $-\Delta \bar{H}_{U}(\mathrm{~kJ} / \mathrm{mol})$ & $-\Delta \bar{S}_{U}(\mathrm{~J} / \mathrm{mol} \mathrm{K})$ & $-\Delta \overline{\mathrm{G}}_{U}(\mathrm{~kJ} / \mathrm{mol})$ & $\Delta T(\mathrm{~K})$ & References \\
\hline \multirow[t]{5}{*}{ Ga-U } & 127.0 & 63.7 & 60.1 & 643-1013 & [7] \\
\hline & 189.0 & 78.7 & 106.3 & $920-1084$ & [8] \\
\hline & 184.3 & 72.1 & 108.6 & $650-985$ & [10] \\
\hline & 173.9 & & & & {$[26]$} \\
\hline & 191.7 & 84.5 & 103.1 & $573-1073$ & Present work \\
\hline \multirow[t]{4}{*}{ In-U } & 25.0 & 2.6 & 22.2 & $626-949$ & [7] \\
\hline & 104.2 & 55.1 & 46.3 & $1273-1553$ & [9] \\
\hline & 122.9 & 72.4 & 46.9 & & {$[15]$} \\
\hline & 147.0 & 92.8 & 49.6 & $573-1073$ & Present work \\
\hline Ga-In-U & 189.9 & 87.1 & 98.5 & $573-1073$ & Present work \\
\hline
\end{tabular}
Ga-In eutectic (3, present work), and gallium (4 and 5) [7,8]

Table 1

Partial thermodynamic functions of $\gamma$-U in saturated alloys with gallium, indium and Ga-In eutectic (partial molar excess Gibbs free energy calculated at $1050 \mathrm{~K}$ ). 


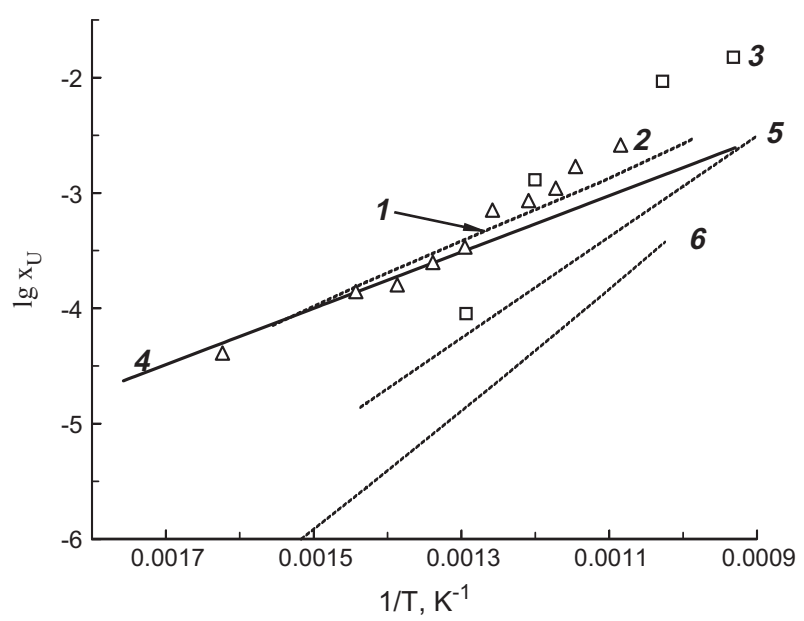

Fig. 6. Solubility of uranium in gallium (1 (line) [7], 2 ( $\Delta$ symbols) [14], 3 ( $\square$ symbols) [28]), Ga-In eutectic (4, present work), and indium (lines 5 [15] and 6 $[7,14])$.

\subsection{Solubility of uranium in Ga-In eutectic alloys}

Uranium solubility in the Ga-In eutectic alloy was estimated using the difference between obtained temperature dependencies of uranium activity and activity coefficients. The temperature dependence of the solubility at $573-1073 \mathrm{~K}$ is described by the following expression:

$\lg X_{\mathrm{U}(\mathrm{Ga}-\mathrm{In})}=-0.34-2.44 \times 10^{3} \cdot T^{-1}$

The obtained dependence is presented in Fig. 6. In the studied temperature range uranium solubility in the Ga-In eutectic lies between the data for Ga and In systems. At higher temperatures the solubility of uranium in the Ga-In alloy is close to that in pure indium but as the temperature is lowered $U$ solubility in Ga-In alloy approaches that in gallium and below $800 \mathrm{~K}$ the data for Ga-In and Ga systems are very close. The fact that only $\mathrm{UGa}_{3}$ intermetallic compound was found in cooled two-phase U-Ga-In alloys also indicates that, al least at lower temperatures, uranium predominantly interacts with gallium. The set of data points 2 in Fig. 6 shows the results obtained from the chemical analysis of equilibrium gallium-based alloys after precipitation of excess intermetallic phases obtained by Johnson and Chasanov [14]. Below $823 \mathrm{~K}$ these data follow closely to the obtained here uranium solubility in the Ga-In eutectic. Below $693 \mathrm{~K}$ uranium solubility in liquid gallium was previously determined only at $616 \mathrm{~K}$ [14]. Shank [27] pointed out that the obtained value likely does not correspond to the equilibrium state. However, the results obtained in the present work agree within the experimental error with that data point.

\section{Conclusions}

Partial thermodynamic functions of uranium, as well as uranium activity and activity coefficients were determined for the first time in low-melting Ga-In eutectic alloy over $500^{\circ}$ range (between 573 and $1073 \mathrm{~K}$ ). Activity and activity coefficients of uranium in alloys with the Ga-In eutectic are close to those in alloys with gallium due to formation of the same intermetallic compound, i.e., $\mathrm{UGa}_{3}$, in both systems. Uranium solubility in In-Ga eutectic based alloys was estimated from the values of determined activity and activity coefficients and it increases with temperature. Below $823 \mathrm{~K}$, the uranium solubility in Ga-In is very close to that in pure gallium but at higher temperatures it occupies an intermediate position between gallium and indium.

\section{Acknowledgements}

The authors thank Dr. A.V. Chukin and Dr. A.K. Schtoltz for their help with X-ray diffraction measurements.

\section{References}

[1] V.A. Lebedev, Selectivity of Liquid Metal Electrodes in Fused Halides, Metallurgiya, Chelyabinsk, 1993. in Russian.

[2] L.V. Gurvich, I.V. Weints, V.A. Medvedev, Thermodynamic Properties of Individual Compounds, vol. 3 (Part 2), Nauka, Moskow, 1981. in Russian.

[3] K.H.J. Buschow, J. Less-Common Met. 31 (1973) 165.

[4] W.C. Moffatt, Handbook of Binary Phase Diagrams, vol. 1, General Electric Co., N.Y., 1976.

[5] P. Gardie, G. Bordier, J.J. Poupeau, J. Le Ny, J. Nucl. Mater. 189 (1992) 85

[6] S. Salhov, G. Kimmel, M.P. Dariel, J. Alloys Comp. 444-445 (2007) 257.

[7] I. Johnson, H.M. Feder, Thermodynamics of Nuclear Materials, IAEA, Vienna, 1962. pp. 319-331.

[8] V.A. Lebedev, V.M. Seregin, A.M. Poyarkov, I.F. Nichkov, S.P. Raspopin, Zh. Fiz. Khim. 47 (1973) 712.

[9] C.B. Alcock, J.B. Cornish, P. Grievenson, Thermodynamics, vol. 1, IAEA, Vienna, 1966. pp. 211-230.

[10] B. Prabhakara Reddy, R. Kandan, K. Nagarajan, P.R. Vasudeva Rao, Thermochim. Acta 366 (2001) 37.

[11] B. Prabhakara Reddy, R. Babu, K. Nagarajan, P.R. Vasudeva Rao, J. Nucl. Mater 271-273 (1998) 395.

[12] J. Wang, X.J. Liu, C.P. Wang, J. Nucl. Mater. 380 (2008) 105.

[13] T. Gouder, L. Havela, M. Diviš, J. Rebizant, P.M. Oppeneer, M. Richter, J. Alloys Comp. 314 (2001) 7.

[14] J.R. Johnson, M.G. Chasanov, Trans. ASM 56 (1963) 272.

[15] V.A. Lebedev, V.M. Seregin, A.M. Poyarkov, I.F. Nichkov, S.P. Raspopin, Zh. Fiz. Khim. 48 (1974) 542.

[16] E. Khacke, J. Krahe, F. Muller, Z. Phys. Chem. 50 (1966) 91.

[17] A. Kisza, W. Trzebiatowski, Bull. Acad. Polon. Sci., Ser. Sci. Chem. 10 (1962) 387

[18] F. Caligara, L. Martinot, G. Duyckerts, Bull. Soc. Chim. Belges 76 (1967) 211.

[19] Y. Sakamura, T. Hijikata, K. Kinoshita, T. Inoue, T.S. Storvick, C.L. Krueger, J.J. Roy, D.L. Grimmett, S.P. Fusselman, R.L. Gay, J. Alloys Comp. 271-273 (1998) 592.

[20] ASM Binary Phase Diagrams, Software, ASM, International (1996).

[21] I.L. Rogelberg, V.M. Beilin, Thermocouple Alloys, Metallurgiya, Moscow, 1983 (in Russian).

[22] V.N. Glushko (Ed.), Thermal Constants of Substances, vol. VIII(Part 1), AN SSSR, Moscow, 1978. in Russian.

[23] L.R. Morss, N.M. Edelstein, J. Fuger (Eds.), The Chemistry of the Actinide and Transactinide Elements, vol. 1, Springer, Dordrecht, 2010.

[24] N.V. Chebotarev, E.S. Smotritskaya, M.A. Andrianov, D.E. Kostyuk, in: H. Blank R. Lindner (Eds.), Plutonium 1975 and other Actinides, North Holland Publishing Co., Amsterdam, 1976, pp. 37-45.

[25] P. Chiotti, V.V. Akhachinkij, I. Ansara, M.H. Rand, The Chemical Thermodynamics of Actinide Elements and Compounds, Part 5, The Actinide Binary Alloys, IAEA, Vienna, 1981.

[26] V.A. Lebedev, Atomnaya Energiya 41 (1976) 33.

[27] F. Shank, Structures of Binary Alloys, Metallurgiya, Moscow, 1973 (in Russian).

[28] W.D. Wilkinson, Uranium Metallurgy, Uranium Corrosion and Alloys, vol. 2, Interscience Publishers, Inc., New York, 1962. 